\title{
Emmanuel CARRÈre. Yoga. Barcelona: Anagrama, 2021, 320 pp.
}

Después de Limónov (2011), después de El reino (2014), la vara quedó muy alta para Emmanuel Carrère. El proyecto de un libro "risueño y sutil" sobre el yoga, como en principio fue concebido por Carrère, difícilmente podría hacerse respetar a la sombra de esas dos obras notables, sin mencionar otras de más larga data como De vidas ajenas (2009), Una novela rusa (2007) y El adversario (2000). Pero el libro risueño y sutil respecto del yoga se fue transformando en el camino, y lo que pudo ser solamente una crónica de un retiro de silencio en un centro de meditación llamado Vipassana, a una hora y media de París, se juntó con lo que Carrère denomina su autobiografía psiquiátrica (concretamente, su internación de cuatro meses en el hospital de Sainte-Anne, electroshocks inclusive, tras su crisis conyugal), que a su vez se juntó con el ataque terrorista a Charlie Hebdo y, en un último giro, con el drama de los refugiados en una isla del Mediterráneo. El resultado de esto es un libro de difícil clasificación: conviven en sus páginas la crónica, la autobiografía, una confesa -e indeterminada- cuota de ficción, algo de ensayo, poemas prestados, cuentos prestados, fragmentos de informes psiquiátricos... No era fácil que a partir de un material tan heterogéneo surgiera un libro propiamente tal. Pero lo cierto es que Yoga lo consigue. Y con largueza.

Para formarse una idea del tipo de libro que es Yoga, lo primero que habría que tomar en cuenta es que en estas páginas Carrère declara sentir un enorme aprecio por la escritura de Montaigne. Más aún, Carrère afirma ser un escritor que está del lado de Montaigne, es decir, de aquellos que narran en zigzag y saborean el camino y siguen una "andadura vagabunda" (72), siempre propensa a intimidades y digresiones, y se complacen al ver que el resultado final de su obra no se parece en absoluto a lo que habían planeado. Para Carrère, esta forma de escribir resulta inseparable de la voluntad de saber "qué significa ser uno mismo" (98) (ese "magma" que somos no se aviene con los discursos lineales). Tal es uno de los fines -si no $\mathrm{el}$ fin-que Carrère se propone alcanzar en las páginas de Yoga, y que por cierto corrobora su filiación a la vereda de aquellos que, como Montaigne, convierten el examen de sí mismos en el objeto de la escritura.

Yoga asume un riesgo importante porque la idea de autoconocimiento es, sobra decirlo, un caldo de cultivo para clichés y narrativas tan estereotipadas como inútiles, más aún si la temática va acompañada de técnicas de meditación, yoga y taichí. Carrère es consciente de esto y de hecho se ríe de la posibilidad de que su relato se confunda con un texto de autoayuda. Nada más lejos de la realidad, por cierto. En parte porque Carrère, si bien transmite una genuina y profunda valoración del yoga, cada cierto rato se encarga de arrojarle baldazos de ironía a sus inmersiones en el silencio y a sus técnicas de respiración. En sus momentos -frecuentes- de escepticismo, considera que esas sofisticaciones no son sino "melindres espiritualistas" (p. 103) y mira con sarcasmo su interés por escrutar lo que ocurre con sus fosas nasales durante la meditación cuando allá afuera, en el mundo real, 
hay experiencias y vidas en las que se ponen en juego cosas cruciales -Hamid y Atiq, por ejemplo, esos chicos afganos que conocen el infierno- y que tiñen de absurdo su aburguesada afición a las técnicas orientales de autoconocimiento.

Son muchas las reflexiones que Carrère elabora acerca del sentido del yoga o de la meditación (ambos términos, nos dice, son intercambiables para él). De hecho, a lo largo de la novela va ensayando una lista de definiciones -llegan a ser más de veinteque "no proceden de libros sino, a mi escala pequeñísima, de una experiencia de primera mano" (p. 287). Ahora bien, aun cuando este recuento se abre en múltiples direcciones, hay un elemento que destaca y que de alguna manera engloba las diversas vivencias e intuiciones referidas por Carrère: la práctica del yoga implica una tensión permanente entre fuerzas opuestas; es más, esa tensión está presente en la misma definición de la palabra yoga, cuyo sentido original según nos recuerda Carrère es el de "sujetar al yugo dos caballos o dos búfalos" (p. 50). Se trata de una idea que a Carrère le resulta especialmente seductora: parece haber una misteriosa liberación en "adelantar los pies hacia atrás" (p. 88); en estirar al máximo la columna, estirarla "como si quisieras empujar el techo con la coronilla" (p. 49), mientras te esfuerzas, al mismo tiempo, por "enraizarla y hacer que la pelvis sienta la atracción del suelo" (p. 49). No es ninguna novedad que Carrère sufre un trastorno bipolar -ya la contraportada del libro lo anuncia-, de modo que la pugna de fuerzas contrarias ha ocupado un lugar preponderante a lo largo de su vida; es el fantasma que ha arrastrado desde siempre y que al final lo llevó a su internación en Sainte-Anne. Resulta comprensible por tanto que Carrère se embriague con esta dimensión del yoga: en esos movimientos que pretenden a la vez avanzar y retroceder, en esos estiramientos a la vez ascendentes y descendentes, se produce el equilibrio de los opuestos, la convivencia de los "búfalos" y de su fuerza indómita; en el yoga se materializa la que quizá sea la máxima aspiración vital de Carrère.

De alguna manera, el libro en su conjunto responde a dicha aspiración. Su composición, que podría parecer dispersa y fragmentada, deja ver una lógica en donde el éxtasis alterna con la miseria, lo sublime con la desesperación, la felicidad con la amargura... Las experiencias atroces de pérdida y desamparo que han vivido los chicos refugiados que Carrère conoce en la isla griega de Leros, colindan con el éxtasis de una borrachera inolvidable y de una música que hace a Carrère tocar el cielo; las tardes felices en el retiro de silencio dan paso al relato de los días y noches infernales en el hospital psiquiátrico; las pulsiones suicidas alternan con expresiones de intensa valoración de la vida. Todo junto. Todo en una estrecha y poderosa vecindad. Sabemos que la existencia de fuerzas contradictorias desgarra la experiencia vital de Carrère, pero en su escritura -como en el yoga- los opuestos no se destruyen, sino que conviven y se miden mutuamente, y en esa interacción es donde se advierte la forma y la unidad particular de esta novela.

En uno de los extremos de este movimiento pendular que sigue la narración está la experiencia del electroshock que vive Carrère. $\mathrm{O}$, para mayor precisión, el regreso del electroshock, la gradual recuperación de la conciencia, acostado en una camilla, en alguno 
de los pabellones del hospital de Sainte-Anne. Cada uno de esos despertares, dice Carrere, "era la eternidad, una eternidad de angustia y espanto" (p. 197), una atroz representación de "la realidad última de la que hablan los místicos" (p. 197), la tiniebla en toda su magnitud. La fuerza opuesta está en las experiencias de superlativa expansión vital -por decirlo de alguna manera- que han dejado una huella en la biografía de Carrère: el episodio en el hotel Cornavin, por ejemplo, donde Carrère y una amante desconocida entran en una espiral erótica donde "yo tenía la sensación de ser ella" y "ella tenía la sensación de ser yo" (p. 79), y que desemboca en la visión que ambos tienen de una luz, una aureola que rodeaba sus cuerpos unidos al máximo, mezclados al máximo, "casi invertidos" (p. 79), y que no era una ilusión ni una autosugestión, era real (p. 79).

Sin embargo, el punto más alto no es este. El punto más alto es Martha, la pianista Martha Argerich a los veinte años, intensa, indómita, genial y entregada a la ejecución de la "Polonesa heroica" de Chopin, en un video en blanco y negro que Carrère recibe como regalo de Frederica, su anfitriona en la isla del Mediterráneo. El hechizo de la música y de las imágenes cautiva de manera inmediata a Carrère, que en su descripción de la escena se eleva a la par que la pianista, hasta llegar al momento cúlmine: el total abandono de Argerich, sus leves sacudidas que en un momento incluso la sacan del encuadre, "el cimbreo de la cabeza" (p. 275) y entonces la sonrisa, "esa sonrisa que viene de la infancia y de la música, esa sonrisa de pura alegría. Dura exactamente cinco segundos, desde los 5'30" a los 5'35', pero en esos cinco segundos vislumbramos el paraíso. Ella lo ha visto durante cinco segundos, pero son suficientes, y al mirar a Martha Argerich tienes acceso a él" (p. 276). Al leer este episodio resulta imposible no pensar en Cortázar, en Rayuela, en El perseguidor. Y también en Clarice Lispector o en André Breton o en cualquier nombre del romanticismo alemán o inglés. La avidez de absoluto los une a todos.

Sin embargo, Yoga es más que el infierno y el paraíso. Yoga es la trastienda de la escritura, la exhibición de sus herramientas, sus mecanismos. Es Carrère confesando -ni más ni menos- cuánto es real y cuánto es inventado en sus personajes; o bien, revelando detalles acerca del montaje de la novela, del "oso", ese intimidante acopio de "archivos disparejos que iban a componer este libro que lee usted" (p. 306), y cómo el "oso", después de un arduo proceso en que "te pones a ensayar, yuxtaponer, cortar, agregar, intercambiar, ensayar trucos..." (p. 306) fue cobrando forma y se convirtió en un libro felizmente imprevisto para su autor.

Yoga es también una secuencia de personajes apasionados y propensos al éxtasis: inolvidable Frederica, poniendo una y otra vez la música de Chopin, embriagada literal y metafóricamente, agarrando del brazo a Carrère y diciéndole con júbilo: "¡escucha, escucha esa pequeña nota!' (p. 228); lo mismo Paul, el editor y amigo de Carrère, que a sus setenta y cuatro años estaba locamente enamorado, que exigía y dispensaba fidelidad absoluta a los escritores que publicaban con él, que hacía doscientas flexiones todos los días, al alba, y a quien Carrère dedica varias páginas, en exclusiva, nada más que para que el lector pueda entender "cómo le brillaban los ojos a Paul" (p. 301), cuando de libros se trataba. 
En fin, está claro que la de Carrère fue una apuesta arriesgada. Unir en un solo libro semejante cantidad de materiales, a lo que hay que sumar el conflicto con su actual exmujer, que previo a la publicación de la novela le exigió - en virtud de un contrato firmado por ambos- que eliminara todas las alusiones a su persona, obligándolo así a introducir una enorme elipsis en el núcleo de lo que se relata en Yoga (pues de la crisis conyugal de Carrère, que fue uno de los detonantes de su crisis psiquiátrica, no se dice casi nada), pues bien, a pesar de lo heterogéneo de sus materiales, a pesar de que la forzada elipsis le resta intensidad al descenso a los infiernos de Carrère, el libro logra salir airoso, las historias se imbrican y alimentan entre ellas, por cierto no en la superficie pero sí en capas más significativas: en la tensión de fuerzas opuestas de la que todas ellas forman parte. No es primera vez que Carrère hace apuestas arriesgadas. A fin de cuentas, años antes se había propuesto escribir la biografía de un escritor ruso, no la de uno muerto sino la de uno vivo, polémico y en ejercicio, que por su parte iya había escrito su autobiografía ${ }^{1}$ ! Y vaya qué librazo resultó ser Limónov. Con Yoga, Carrère otra vez gana la partida.

\title{
https://doi.org/10.32735/S0718-2201202100053961
}

\author{
Niels Rivas Nielsen \\ Departamento de Literatura, Universidad Adolfo Ibáñez. \\ niels.rivas@uai.cl
}

\footnotetext{
${ }^{1}$ Soy yo, Edichka. Limónov, Eduard. Traducción de Ana Guelbenzu. Barcelona: Marbot ediciones, 2014
} 